\title{
SÍNDROME MICCIONAL AGUDO E INMEDIATO POST-RTU: UN CASO DE CISTOPATÍA INCRUSTANTE
}

\author{
C. GONZÁLEZ ENGUITA, R. MONTERO RUBIO, Ma‥J. CANCHO GIL, \\ F. CRESPÍ MARTÍNEZ, I. BRAVO FERNÁNDEZ, A. BARAT CASCANTE*, \\ R. VELA NAVARRETE \\ Cátedra y Servicio de Urología. *Servicio de Anatomía Patológica. Fundación Jiménez Díaz. \\ Universidad Autónoma. Madrid. \\ Actas Urol Esp. 27 (1): 47-54, 2003
}

\section{RESUMEN \\ "SÍNDROME MICCIONAL AGUDO E INMEDIATO POST-RTU: UN CASO DE CISTOPATÍA INCRUSTANTE"}

Presentamos un caso de sintomatología miccional aguda e inmediata después de RTU de neoplasia vesical. El cuadro miccional, de carácter irritativo, cursó con cultivo de orina positivo a Enterococo y Staphylococo. La exploración vesical bajo anestesia (EBA) descartó la afección uretral (estenosis). Todavía sin cicatrizar, se observó una mucosa vesical edematosa, congestiva y sangrante, cubierta por una extensa calcificación blanquecina. Con la impresión diagnóstica de cistopatía incrustante se realizó RTU de toda la mucosa vesical afecta (legrado). La anatomía patológica confirmó el diagnóstico. Se instauró tratamiento antibiótico (Amoxi-Clavulánico), en diferentes pautas, hasta que el cultivo de orina se negativizó.

Se realiza revisión de los aspectos clínicos, diagnósticos y terapéuticos de esta cistopatía, no muy frecuente, donde las bacterias ureolíticas son los microorganismos responsables, fundamentalmente Corynebacterium ureolíticum, y donde la instrumentación endourológica está íntimamente relacionada con el desarrollo de la cistopatía.

PALABRAS CLAVE: Cistopatía incrustante. Instrumentación endoscópica. Infección urinaria. Corynebacterium ureolíticum.

\section{ABSTRACT}

“ACUTE AND PROMPT URINATION SINDROM AFTER TRANSURETHRAL RESECTION (TR): A CASE OF INCRUSTANT CYSTOPHATIE"

The authors present a case of acute and prompt symptomatic irritative urinary cistitis after transurethral resection (TR) of bladder cancer. The clinical presentation, like a irritative sindrome, was with a positive urine cultive to Enterococci and Staphylococcus. The phisical examination, under general anesthesia (EBA), eliminated the urethral injury or the meatus trauma, so the urethral stenosis. The bladder view, in scaring processing yet, was congestive, bledding and edematous; an extensive white calcification was covering all the mucose surface bladder. The presumptive diagnosis was incrusted cystophatie (cystitis) and a transurethral resection (TR), along total bladder mucosa, was made so the result of pathological examination was sure. Intravenous and oral antimicrobial agent (Amoxicillin-Clavunan), in differents ways, was instaured like a treatment, to achieve a negative urinary cultive, to eradicate the bacterial agents.

We made a revision of the most important aspects in the clinical presentation, laboratory diagnosis and therapy, in this cystophatie that is not frecuent, where the ureolitic bacterial agents have the responsibility, main Corynebacterium urealiticum, and where the recent urologic surgery or instrumentation, is narrowly related with the development of this cystophatie.

KEY WORDS: Incrustant cystophatie. Endoscopic instrumentation. Urinary infection. Corynebacterium ureoliticum. 
$\mathrm{L}$ a cistopatía incrustante es una entidad vesical originada por la infección urinaria de bacterias con acción ureolítica. Sobre una pared vesical enferma, y por lo tanto fácilmente vulnerable, se depositan sales calcáreas calcificándose la superficie de la vejiga. Esta situación provoca un intenso y agudo sindrome miccional de carácter irritativo.

Es una afección poco frecuente que se debe sospechar después de toda actuación endo-urológica del trato urinario inferior ${ }^{1,2}$. La farmacología actual (antibióticos, acidificantes urinarios, ácido acetohidroxámico,...) logra curar la infección. En un cierto porcentaje de casos, algunas circunstancias hacen la curación imposible, el sufrimiento del paciente se perpetua y el recurso excepcional, la derivación urinaria, es la única alternativa eficaz ${ }^{2}$. Excluyendo la vejiga se deja inoperante el proceso infectivo al desaparecer las bacterias. Sin orina en vejiga no hay proceso infectivo ureolítico ni incrustante vesical.

\section{CASO CLÍNICO}

Varón de 58 años, taxista de profesión y gran fumador (más de dos cajetillas/día), hipertenso y diabético en tratamiento con antidiabéticos orales. Historia de litiasis renoureteral oxalocálcica desde hace años (cólicos renales y expulsión de cálculos).

Por un episodio de hematuria monosintomática con coágulos, se le diagnostica de neoformación vesical papilar multifocal que ocupa prácticamente toda la vejiga acompañada de citología de orina positiva (carcinoma urotelial) (Figs. 1, 2, 3 y 4). Se le realiza RTU del tumor vesical programando una segunda Exploración Bajo Anestesia (EBA), "second look", al mes de la RTU (a la cicatrización), con el fin de confirmar la ausencia de restos tumorales. La anatomía patológica fue: carcinoma urotelial papilar (estadío A de Jewet-MarshallSystem, grado citológico 2).

Al retirar la sonda vesical presenta polaquiuria intensa (micciones cada 5-10 minutos), continua (día y noche), escozor miccional y tenesmo sin hematuria. Pensando en infección urinaria, sin cultivo de orina previo, se inicia tratamiento antibiótico con quinolonas, que no mejoran la sintomatología. La citología de orina en el post-operatorio inmediato es negativa. Se piensa en meatoestenosis o estenosis uretral post-inflamatoria

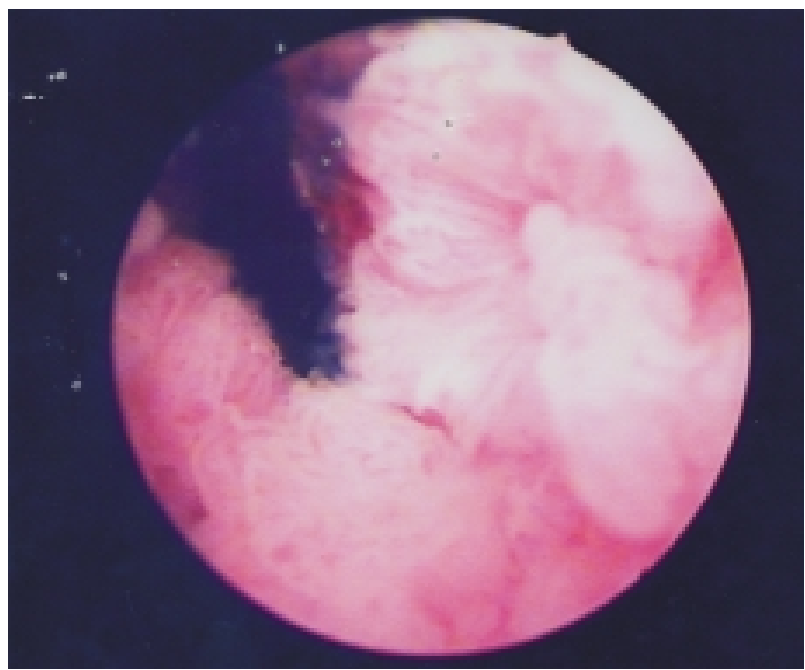

FIGURA 1. Imagen de la cistoscopia del caso clinico. Tumor papilar de largas papilas que ocupa gran superficie vesical.

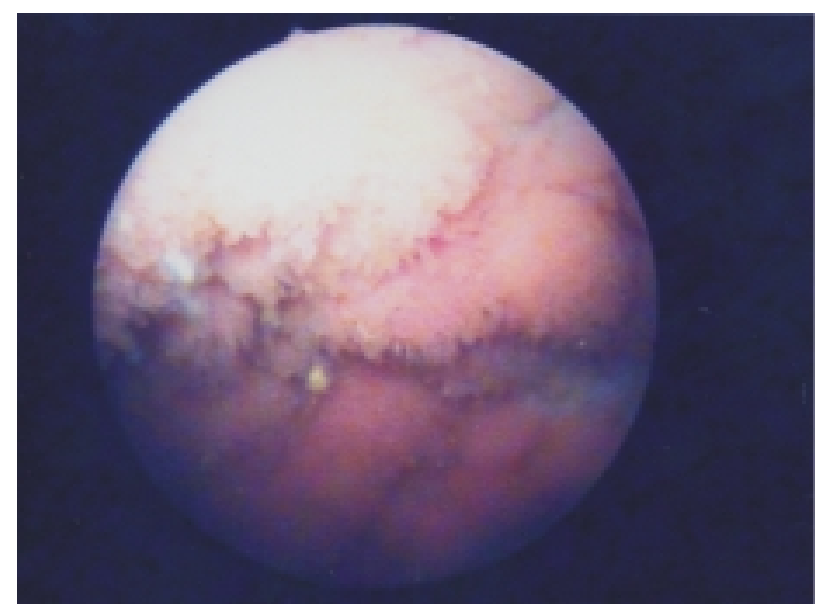

FIGURA 2. Imagen de la cistoscopia del caso clínico. Se puede observar calcificación blanquecina amarillenta sobre la superficie tumoral vellosa.

aguda tras RTU descartándose en la exploración visual y endoscópica. El cultivo de orina es positivo a Enterococo y el pH urinario de 6,7. Con posterioridad se identificará Estaphylococo.

La exploración bajo anestesia (EBA) prevista (second look), demuestra ausencia de restos tumorales y una mucosa vesical cubierta, casi en su totalidad, por una gruesa capa blanquecina, irregular y dura (calcificación), entre zonas edematosas, bullosas y sangrantes, sobre superficie vesical no cicatrizada. Se practica RTU vesical ("legrado") de toda la superficie afecta. 


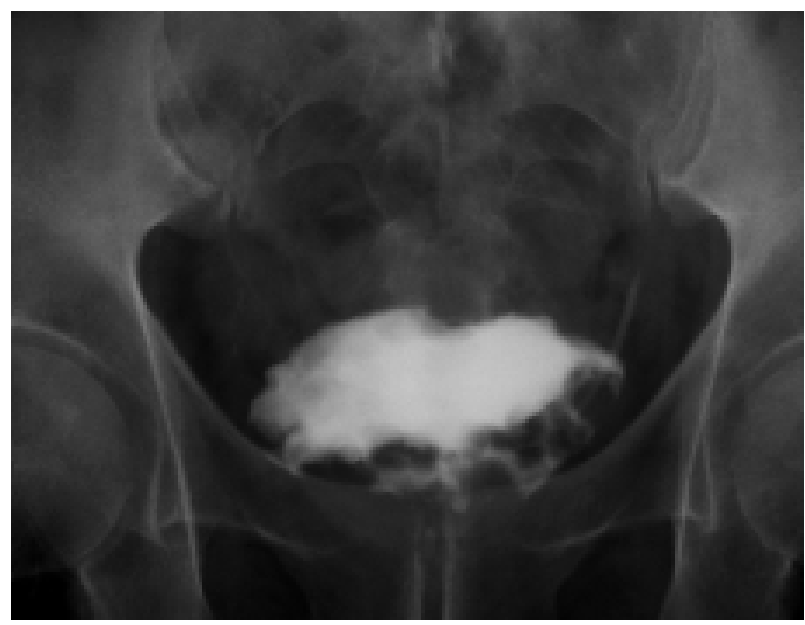

FIGURA 3. Cistografia. Defecto de replección múltiple sospechoso de neoformación vesical multifocal. Ausencia de compromiso ureteral bilateral.

La descripción microscópica del anatomo-patólogo fue de "intensa reacción inflamatoria crónica que incluye abundantes eosinófilos y células gigantes multinucleadas de tipo cuerpo extraño, presencia de material granular calcificado (carbonato apatita amorfo), siderófagos, zonas muy vascularizadas (tejido de granulación) y focos de necrosis. "Atipia citológica", compatible con Cistopatía Incrustante.

Los cultivos posteriores siguieron siendo positivos a Enterococcus spp y en una sola ocasión Staphylococcus coagulasa negativo, a pesar de las diferentes pautas antimicrobianas con Amoxi/ Clavulánico. Nunca se identificó Corynebacterium ureoliticum, como se sospechó inicialmente, a pesar de insistir al microbiólogo en su búsqueda. $\mathrm{El} \mathrm{pH}$ urinario fue siempre alcalino $(>6,5)$.

En las primeras semanas la clínica miccional de carácter irritativo sólo mejoró en intensidad. Cuando el cultivo se negativizó la mejoría fue más evidente aunque sin llegar completamente a desaparecer.

En la actualidad después de seis meses no hay evidencia de infección urinaria ni de recidiva tumoral, con citología de orina negativa. La curación vesical cursa con vejiga retráctil, calcificación residual, que provoca uropatía obstructiva bilateral manifiesta con cifras normales de creatinina (Fig. 5). Paradógicamente la clínica miccional irritativa es discreta. Para obtener la curación definitiva se intuye que necesitará derivación urinaria
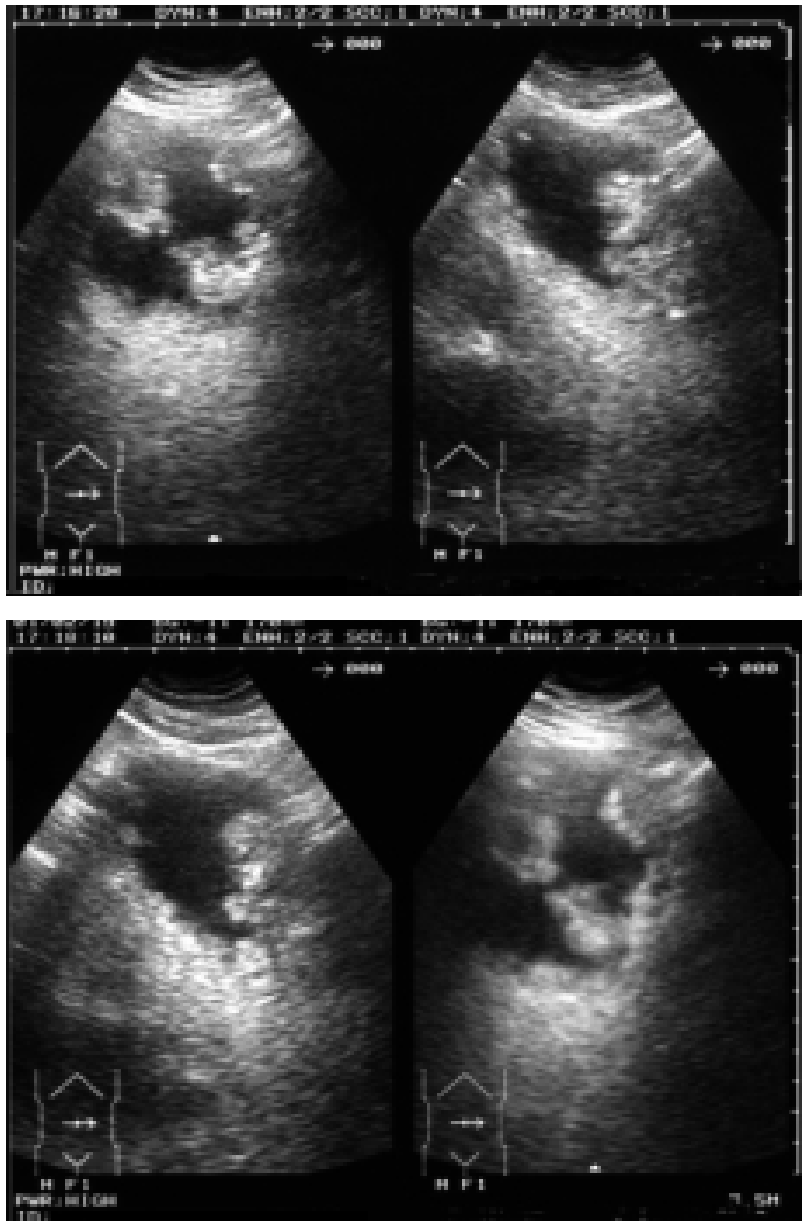

FIGURA 4. Ecografia vesical del caso clinico. Gran tumor vesical

(ureterosigmoidostomía bilateral), posiblemente sin cistectomía, necesitando la vejiga vigilancia oncológica.

\section{DISCUSIÓN}

La sintomatología miccional de carácter irritativo (polaquiuria, escozor, tenesmo vesical,...) después de instrumentación endoscópica del tracto urinario inferior, presume la existencia de infección urinaria o estenosis aguda post-inflamatoria uretral, fundamentalmente del meato (meatitismeatoestenosis). El diagnóstico en el caso de infección, es directo a través del estudio en fresco de la orina recién emitida (sedimento urinario y $\mathrm{pH}$ ) y cultivo de orina. Si se trata de una meatitis se identifica claramente en la exploración física o endoscópica. El tratamiento antibiótico resuelve con satisfacción los casos de infección y la dilatación uretral la estrechez de la uretra. 

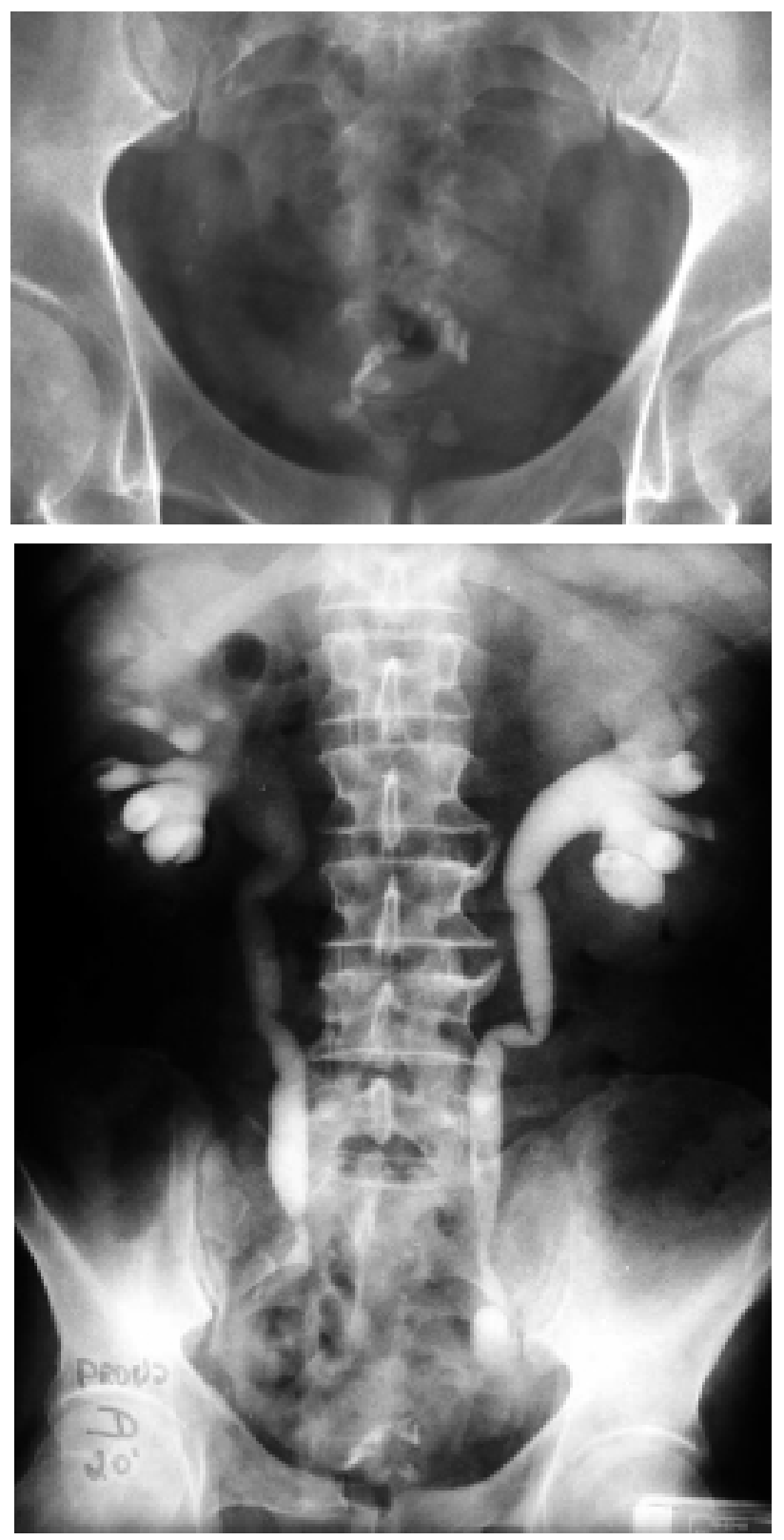

La cistopatía incrustante es mencionada por Algaba $(1997)^{1}$ como aquella lesión de la vejiga caracterizada por el depósito de material cálcico sobre la superficie vesical. Según Cifuentes $(1989)^{2}$, la cistitis incrustada o incrustante no constituye por sí misma una entidad nosológica y puede ser una etapa evolutiva de otro tipo de cistitis. Se caracteriza por la precipitación de sales calcáreas sobre lesiones vesicales pre-existentes precisando que se reúnan tres condiciones:

1. Que exista infección urinaria por bacterias ureolíticas,

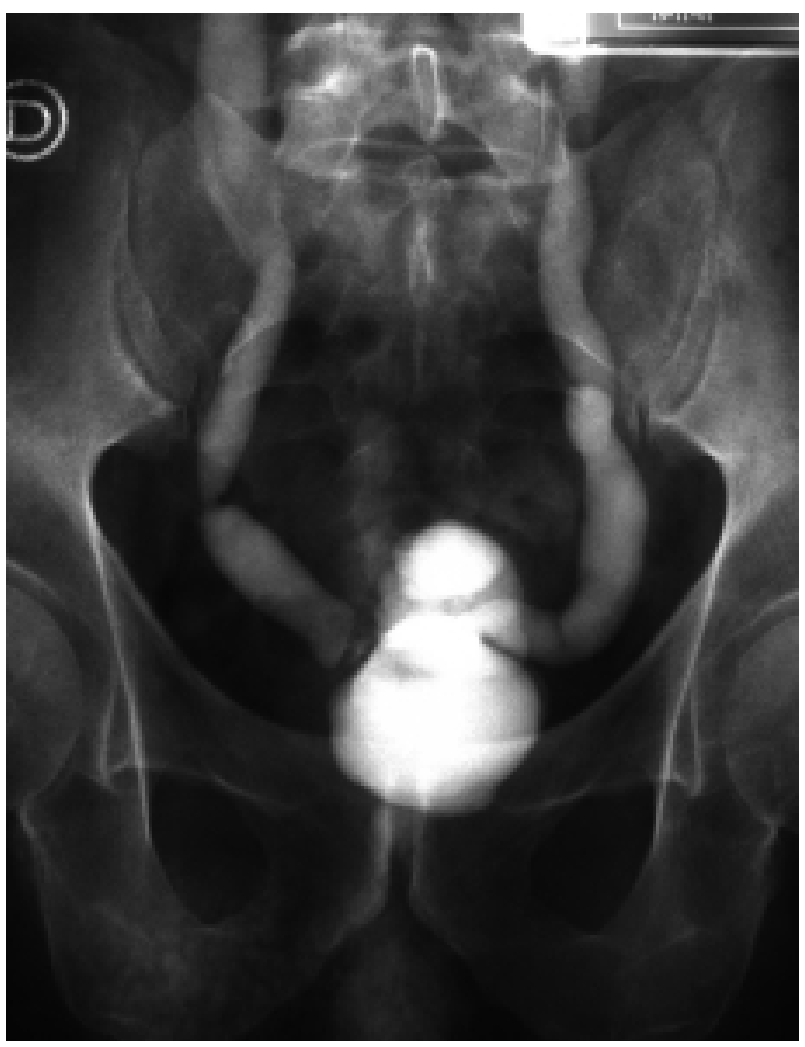

FIGURA 5. Rx simple de abdomen que muestra calcificaciones residuales en vejiga. Vejiga retráctil y uropatia obstructiva bilateral.

2. Gue se produzca una intensa alcalinización urinaria $(\mathrm{ph}>7)$.

3. Que exista un epitelio vesical alterado donde puedan precipitar las sales cálcicas.

Sin embargo han sido descritos casos de cistopatía incrustante que no cumplen estas premisas, es decir que se han desarrollado sin la presencia de bacterias ureolíticas y/o orinas no alcalinas. Huguet Pérez publica en $1999^{3}$ que sólo el $29 \%$ de todos los casos que presenta (37 casos) cumplen estas tres condiciones. 
Clínicamente es una afección que hace sufrir intensamente a los pacientes que la padecen por grandes molestias miccionales. Es una sintomatología miccional de carácter irritativo muy acusada, polaquiuria, escozor, dolor miccional muy intenso y/o hematuria. La orina es turbia, con mucosidad abundante y un fuerte olor amoniacal. Es patognomónico la expulsión de concreciones blanquecinas, blandas e irregulares durante una crisis miccional. Puede desarrollarse de manera espontánea pero sobre todo después de una exploración diagnóstica o tratamiento endourológico o endoscópico si no se ha realizado o ha sido ineficaz la profilaxis antimicrobiana ${ }^{2,4}$.

La visión endoscópica vesical es de incrustaciones calcáreas, zonas blanquecinas que cubren y sobresalen sobre la mucosa vesical, de carácter irregular siendo la incrustación en sábana o en superficie muy rara, como una áspera membrana calcárea (Fig. 6). Vicente et al. ${ }^{5}$ distingue dos tipos endoscópicos de cistitis incrustante alcalina: la localizada, membranosa o algodonosa y la difusa. Las calcificaciones si son muy abundantes pueden ser incluso visibles en la Rx simple de aparato urinario (Fig. 5).

Los microorganismos deben ser ureolíticos, es decir, que produzcan una ureasa activa. La ureasa desdobla la urea produciendo gran cantidad de amoniaco que origina intensa alcalinización urinaria. En este $\mathrm{pH}$ urinario precipitan las sales calcáreas (fosfato y carbonato) y amónico magnésicas). Otro componente de las incrustaciones puede ser el urato amónico (Fig. 7) ${ }^{2,6}$.

Los agentes causales más frecuentes son Proteus (mirabillis, vulgari o morgani), con frecuencia Klebsiella y algunas variedades de Pseudomona aeruginosa, Enterobacter y Serratia. La mayoria de las infecciones son mixtas. Enterococo si bien es frecuente, tiene un poder ureolítico débil, variable e inconstante, y podría no tener gran importancia en la génesis de la cistopatía incrustante. Con frecuencia se identifican gram-positivos como Estaphylococo y Corynebacterium $^{2-4}$.

En 1985 las investigaciones de Soriano, Cifuentes y cols. ${ }^{7}$ determinaron que la variedad Corynebacterium del grupo $\mathrm{D}_{2}$ provoca intensa alcalinización de la orina por fermentación amoniacal. Corynebacterium ureoliticum, así denomi- nado a partir de este momento, fue de difícil diagnóstico, considerándola como la bacteria responsable de esta cistopatía.

Corynebacterium ureoliticum produce una infección predominantemente tisular. Actúa y se desarrolla especialmente en la mucosa vesical, en ocasiones con escasa infección urinaria de difteroides y retardada aparición de colonias en siembras de orina. Tiene gran tendencia a adherirse a estructuras cristalinas formando pequeños acúmulos entre células epiteliales y la intensa mucosidad que tiene la orina de estos pacientes. Esto significa la difícil identificación en el estudio en fresco de la orina recién emitida y los cultivos negativos, de no insistir en la búsqueda de Corynebacterium ${ }^{4}$.

En el caso que se presenta predomina el cultivo positivo a Enterococo y sólo en una ocasión crece Estaphylococo. Se duda de la responsabilidad del Enterococo por su escasa actividad ureolítica y se responsabiliza la acción del Estaphylococo. El departamento de microbiología no identifica a Corynebacterium a pesar de su búsqueda y de su sospecha.

La histopatología de la cistopatía incrustante fue especialmente estudiada por Francois $(1914)^{2,9}$. La zona inflamatoria es fundamentalmente un granuloma inflamatorio polimorfo que presenta calcificación. La zona superficial es tejido necrosado con inclusiones calcáreas. Por debajo de este tejido necrosado hay numerosos vasos sanguíneos trombosados con gran infiltración de linfocitos y leucocitos polinucleares y grandes acúmulos microbianos. Los signos inflamatorios van disminuyendo a medida que se profundiza hacia la capa muscular. En plena submucosa se identifica no sólo fosfato cálcico sino también cristales de Fosfato Amónico Magnésico. Algaba la describe en su libro como el depósito e incrustaciones de sales cálcicas sobre lesiones ulceradas, que pueden llegar a situarse en la submucosa y la muscular ${ }^{1}$. Microscópicamente hay reacción inflamatoria crónica, tejido de granulación y a veces reacción granulomatosa a cuerpo extraño.

Nuestro caso fue informado como corion y capa muscular verdadera con intensa reacción inflamatoria crónica, que incluye eosinófilos y células gigantes multinucleadas de tipo cuerpo extraño, frente a la presencia de material granular calcifica- 


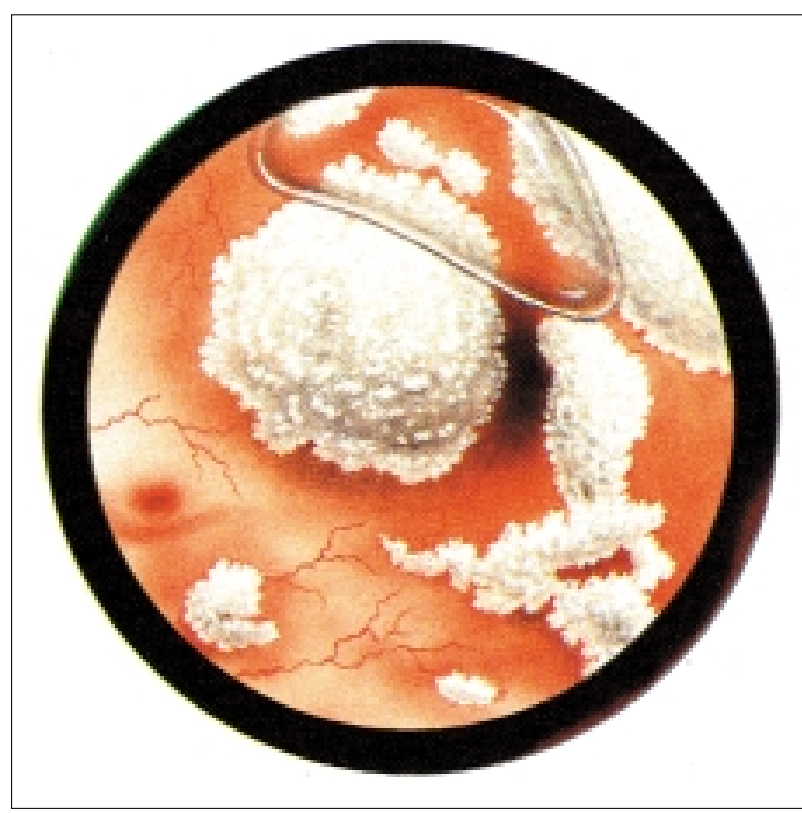

FIGURA 6. Aspecto endoscópico de una tipica cistitis incrustada. Del libro Cistitis y Cistopatias (2 $2^{\underline{a}}$ Ed. L. Cifuentes Delatte ${ }^{2}$.

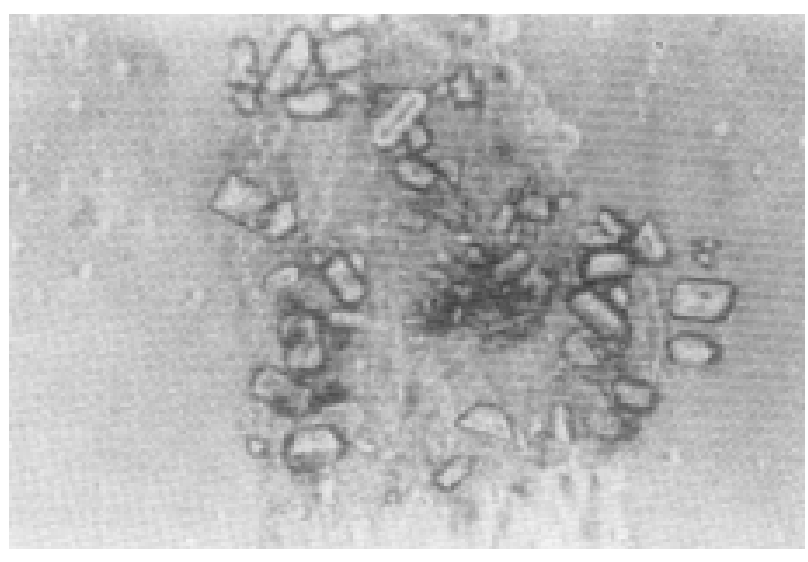

FIGURA 7. Cristales de struvita (FAM) con total ausencia de bacterias detectables con el microscopio de contacto de fases, haciendo sospechar la presencia de Corynebacterium $D_{2}$. Del libro Cistitis y Cistopatias ( $2^{\underline{a}}$ Ed. L. Cifuentes Delatte 1989²).

do. Siderófagos y frecuentes zonas muy vascularizadas constituidas por tejido de granulación y focos de necrosis. Calcificación distrófica con reacción giganto-celular de tipo cuerpo extraño (Fig. 8).

La instrumentación endourológica o endoscópica está íntimamente relacionada con el desarrollo de esta cistopatía, sobre todo sino se ha tenido la precaución de hacer profilaxis antimicrobiana con el antibiótico adecuado, y en muchas ocasio- nes incluso habiéndola realizado de manera correcta. No olvidemos que la instrumentación del aparato urinario de manera ascendente o retrógrada desde la uretra, arrastra bacterias que pueden ocasionar cuadros sépticos importantes, de ahí la obligatoriedad de profilaxis ante todo acto urológico de esta índole y a este nivel (cistoscopia, dilatación uretral, uretrografias, RTU,.... $)^{10-13}$.

También se relaciona la cistopatía incrustante muy directamente con la existencia de tumor vesical. En ocasiones la superficie tumoral vellosa está cubierta de calcificaciones blanquecinas que no son sino depósitos de sales calcáreas ${ }^{2}$ (Fig. 2) y sobre todo se puede desarrollar sobre la superficie cruenta o necrótica vesical después de la RTU. Ambas circunstancias se presentan en el caso que se ilustra, es decir, el propio tumor ya tenía calcificaciones en su superficie, sobre diferentes papilas tumorales (Fig. 2), pero en ningún momento se sospechó que pudiera desarrollar un cuadro de cistopatía incrustante tras la RTU.

¿Cómo tratar la Cistopatía Incrustante?

Inicialmente se debe tratar la infección y crear un medio inhóspito para el desarrollo de la acción ureolítica de las bacterias. El antibiótico debe ser elegido según el microorganismo responsable, de ahí la importancia de su identificación ${ }^{12,15}$.

El Ácido Acetohidroxámico, con acción inhibidora de la ureasa impide la acción ureolítica de estas bacterias. Tiene una estructura química muy similar a la urea y por lo tanto compite con ella en la acción de la ureasa, inhibiendo la acción de ésta y disminuyendo la creación de amoniaco. La ausencia de un $\mathrm{pH}$ alcalino, es decir, una orina no alcalina, no favorece la precipitación de las sales calcáreas. La dosis habitual es de 5-20 $\mathrm{mg} / \mathrm{Kg}$. No destruye las bacterias, pero altera las condiciones ureolíticas del medio e impide su desarrollo.

El pH urinario debe ser ácido para impedir la precipitación de sales calcáreas. Como acidificantes, aunque existen muchas fórmulas, sólo se puede administrar por vía oral la Vitamina C con escaso poder de acidificación. Preparados como el Cloruro amónico, podrían conseguir una secreción renal más ácida pero son muy mal tolerados por vía oral. La instilación de sustancias ácidas a través de una sonda vesical (solución G) junto a los antibióticos han sido utilizadas en muchas 


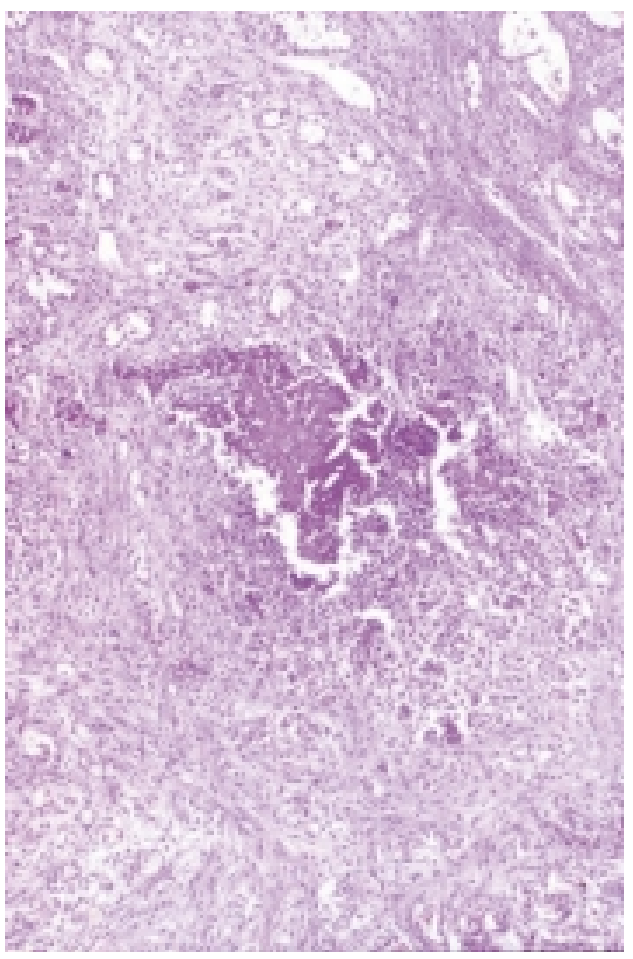

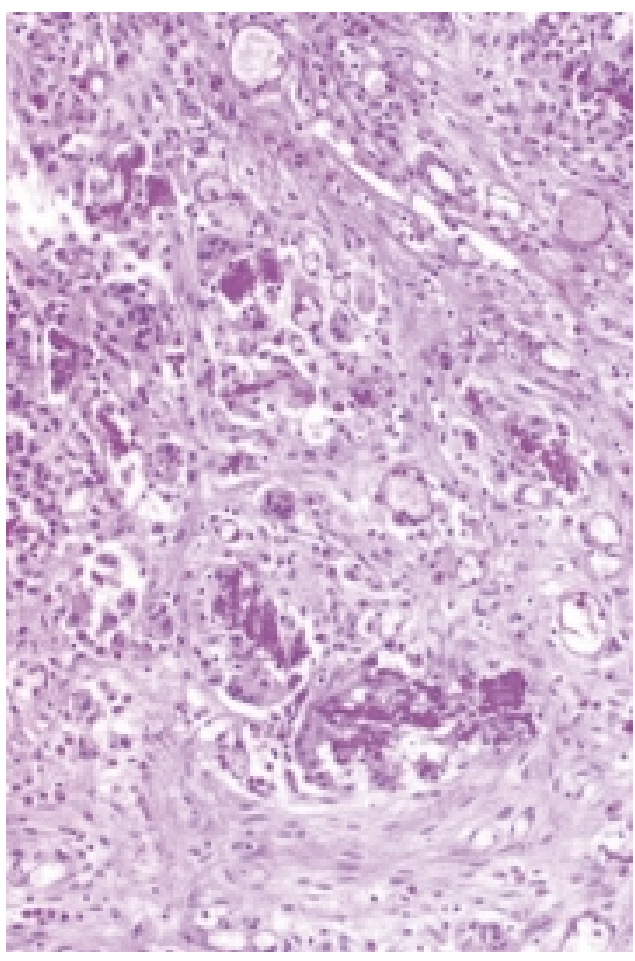

FIGURA 8. Corion y capa muscular verdadera con intensa reacción inflamatoria crónica que incluye eosinófilos y células gigantes multinucleadas de tipo cuerpo extraño, frente a la presencia de material granular calcificado. Siderófagos y múltiples zonas muy vascularizadas, constituidas por tejido de granulación y focos de necrosis. Calcificación distrófica con reacción giganto-células de tipo cuerpo extraño. ocasiones $^{2}$. La solución G (Suby y Albrigth) es una solución tampon $\mathrm{pH}=4$, que disuelve las concreciones alcalinas inorgánicas y por la adición de una pequeña cantidad de óxido magnésico no causa irritación de la mucosa del tracto urinario. Esta solución consta de los siguientes preparados:

$\begin{array}{ll}\text { Ácido cítrico (monohidrato) } & 32,3 \mathrm{gr} \\ \text { Carbonato sódico (anhidro) } & 4,4 \mathrm{gr} \\ \text { Óxido de } \mathrm{Mg} \text { (anhidro) } & 3,8 \mathrm{gr} \\ \text { Agua destilada hasta } & 1000 \mathrm{cc} .\end{array}$

Esta Solución G tiene además propiedades bactericidas frente al Proteus, Coli y Enterococo al disminuir el $\mathrm{pH}$ hasta cifras muy bajas ${ }^{2}$.

Finalmente se suele realizar una RTU de la pared vesical afecta con el fin de eliminar las incrustaciones calcáreas. La RTU debe realizarse en profundidad, ya que se ha comentado como estos depósitos cristalinos están no sólo en la mucosa sino en el tejido vesical, sobretodo si se trata del Corynebacterium ${ }^{4}$.

\section{CONCLUSIONES}

1. Importancia de la Profilaxis Antimicrobiana ante todo proceso de exploración diagnóstica o tratamiento endoscópico y endourológico.

Debe ser pauta habitual realizar Profilaxis
Antimicrobiana ante cualquier actuación urológica del tracto urinario inferior sobre todo si se realiza de manera ascendente o retrógrada, es decir desde la uretra. Desde la uretra se arrastran bacterias, allí existentes, que pueden pasar a la sangre y producir bacteriemia y sepsis. Y no sólo en cirugía endoscópica sino también en exploraciones diagnósticas o actuaciones terapéuticas (cistoscopia, uretrografía, dilatación uretral,...). Se seguirán los principios de Burke de la Profilaxis Antimicrobiana Quirúrgica ${ }^{11}$. El antibiótico irá dirigido pensando en bacterias gram-negativas que son las habituales en este campo. Existen pautas establecidas por la Asociación Europea de Urología (EAU) para el tratamiento de las infecciones urinarias y para la Profilaxis Antimicro-biana Quirúrgica que recoge los Guidelines (2001) $)^{12-15}$.

\section{Importancia del Diagnóstico de Presunción de} Cistopatía Incrustante ante todo Síndrome Miccional Agudo e Inmediato post-RTU.

La sintomatología miccional aguda e inmediata después de RTU, de carácter irritativo, hace pensar inicialmente en infección urinaria y suele ceder con la antibioterapia habitual. Otra cir- 
cunstancia muy común es la meatitis y meatoestenosis como consecuencia de la fricción y acción mecánica de los elementos endoscópicos, sobre todo sino se ha tenido la precaución de recomendar la autodilatación meatal en los días posteriores a la retirada de la sonda vesical.

A pesar de ser una entidad poco común, no se debe olvidar el diagnóstico de cistopatía incrustante, como lo demuestra el caso clínico que se presenta, sobre todo una vez descartada la lesión uretral y ante la persistencia de los síntomas miccionales a pesar del antibiótico.

\section{Búsqueda e Identificación del Corynebacterium urealiticum.}

Es una bacteria de comportamiento peculiar, de crecimiento lento y difícil identificación en la orina vista al microscopio en fresco y en cultivos habituales. Se debe sospechar ante situaciones clínicas similares a las descritas. Por ello, se debe orientar al microbiólogo e insistir en su identificación si las condiciones de la orina y la clínica del paciente hacen sospechar su participación. En el caso que se presenta, no creció Corynebacterium, siempre los cultivos fueron positivos a Enterococo y en una sola ocasión a Estaphylococco; sí fueron bacterias ureolíticas sobre todo Estaphylococco y conociendo que de forma muy débil Enterococo, y el $\mathrm{pH}$ alcalino.

4. El tratamiento debe incluir todas las pautas ya señaladas:

1. Antibióticos.

2. Sustancias acidificantes de la orina, bien por vía sistémica o local mediante instilaciones vesicales.

3. Ácido ácetohidroxámico (impide la acción ureolítica de las bacterias).

4. RTU de la pared vesical.

5. Sin olvidar el tratamiento de la enfermedad de base que ha convertido a la vejiga en vulnerable; en el caso que se presenta el tumor vesical.

\section{REFERENCIAS}

1. ALGABA F, MORENO A, TRIAS I.: Cistitis incrustantes. En Uropatología no tumoral. Capítulo II: Vía urinaria inferior. Patología inflamatoria de la vía urinaria inferior. Pulso Ediciones, S.A. Barcelona 1977: 108.
2. CIFUENTES DELATTE L.: Cistitis incrustadas. Del libro Cistitis y Cistopatías, (2 ${ }^{\underline{a}}$ Ed.). Ed. Bok, S.A. Madrid 1989: 83-90.

3. HUGUET PÉREZ J, SALVADOR BAYARRI J, RODRÍGUEZ VICENTE J.: Cistopatía incrustante. ¿Siempre alcalina?. Arch Esp Urol 1999; 52 (2): 157164.

4. VELA NAVARRETE R.: Cistitis incrustantes: nuevos hallazgos clínico-bacteriológicos. Rev Clin Esp 1986; 178: 153.

5. VICENTE J, ALGABA F, DEL PORTILLO L.: Macro y microscopia de las cistopatías (III). Cistopatía incrustante. An Fund Puigvert 1980; 10: 68.

6. GARCÍA DE LA PEÑA E.: Cálculos urinarios con urato amónico. Frecuencia y aspectos morfoestructurales. Estudio con microscopio de polarización. Tesis Doctoral dirigida por el Dr. Cifuentes Delatte, Curso 1977-78. Universidad Autónoma. Madrid.

7. SORIANO GARCÍA F.: Infecciones urinarias por Corynebacterium del grupo $\mathrm{D}_{2}$. Med Clin (Barcelona) 1985; 86: 345.

8. CIFUENTES DELATTE L, VELA NAVARRETE R, SORIANO GARCÍA $F$ et al.: Infecciones urinarias por difteroides ureolíticas con cultivos falsamente negativos. Arch Esp Urol 1984; 37: 329.

9. FRANÇOIS J.: La cystite incrustée. $J$ d'Urol 1914: 535.

10. KUNIN CM.: En Urinary tract Infections: detection, prevention and management. $5^{\text {th }}$ Ed. Baltimore: Williamn \& Wilkins 1997: 363.

11. BURKE JF.: The effective period of preventive antibiotic action in experimental incisions and dermal lesions. Surgery 1961; 50: 161-168.

12. The Medical Letter. On drugs and therapeutics: antimicrobial prophylaxis in surgery. The Medical Letter. On drugs and therapeutics. (Issue 1060), august 1999; 41 : 27.

13. The Medical Letter. On drugs and therapeutics: the choice of antibacterial drugs. The Medical Letter. On drugs and therapeutics. (Issues 1064), october 1999; 41: 22.

14. VELA NAVARRETE R.: Uso profiláctico de Antimicrobianos en Urología. En I Seminario de Urofarmacología: antimicrobianos en urología. 1994. Libro del Sílabus. Ed.: Cátedra y Servicio de Urología. Fundación Jiménez Díaz. Universidad Autónoma. Madrid.

15. NABER KG, BERGMAN B, BISHOP MC, BJERKLUND JOHANSEN TE, BOTTO H, LOBEL B, JIMÉNEZ CRUZ F, SELVAGGI FP.: Perioperative antibacterial prophylaxis in Urology. Guidelines on urinary and male genital tract infections of EAU. Ed. EAU 2001: 57-63.

Dra. C. González Enguita

C/ Costa Brava, 26 - Blq. 2, 3ํA

28034 Madrid

(Trabajo recibido el 21 febrero de 2002) 